\title{
Myocardial haemorrhage after acute reperfused ST-elevation myocardial infarction evolves progressively and contributes to the early bimodal pattern in T2-relaxation time: advanced imaging and clinical significance
}

\author{
David Carrick ${ }^{2,1^{*}}$, Caroline Haig ${ }^{3}$, Nadeem Ahmed ${ }^{2}$, Samuli M Rauhalammi², Guillaume Clerfond ${ }^{2}$, jaclyn carberry ${ }^{2}$, \\ Ify Mordi ${ }^{2}$, Margaret McEntegart ${ }^{1,2}$, Mark Petrie ${ }^{1}$, Hany Eteiba', Stuart Hood ${ }^{1}$, Stuart Watkins', Mitchell Lindsay ${ }^{1}$, \\ Ahmed Mahrous ${ }^{1}$, Paul Welsh², Naveed Sattar ${ }^{2}$, lan Ford ${ }^{3}$, Keith G Oldroyd ${ }^{2,1}$, Aleksandra Radjenovic ${ }^{2}$, \\ Colin Berry ${ }^{2,1}$
}

From 19th Annual SCMR Scientific Sessions

Los Angeles, CA, USA. 27-30 January 2016

\section{Background}

The time-course and relationships of myocardial haemorrhage and oedema in survivors of acute ST-elevation myocardial infarction (STEMI) are uncertain.

\section{Methods}

30 STEMI patients (mean age 54 years; 25(83\%) male) treated by primary percutaneous coronary intervention underwent serial cardiac magnetic resonance imaging: 4 12 hours, 3 days, 10 days and 7 months post-reperfusion. Native T2 and T2* were measured in regions-of-interest in remote and injured myocardium. Myocardial haemorrhage was taken to represent a hypointense infarct core with a T2* value <20 ms. Public registration: NCT02072850.

\section{Results}

Myocardial haemorrhage occurred in 7(23\%), 13(43\%), 11 (33\%), and 4(13\%) patients at $4-12$ hours, 3 days, 10 days and 7 months, consistent with a unimodal pattern. The corresponding amounts of myocardial haemorrhage (\% LV mass) during the first 10 days post-MI were (median, IQR): 2.7(0.0, 5.6), 7.0(4.9, 7.5), 4.1(2.6, 5.5); $\mathrm{p}<0.001)$. Myocardial oedema (\% LV mass) had a unimodal evolution in all patients $(\mathrm{p}=0.001)$. In patients without hemorrhage, infarct zone T2 values (ms) increased progressively during the first 10 days (62.1(2.9), 64.4(4.9), 65.9 (5.3) ( $<$ 0.001). Alternatively, in patients with myocardial haemorrhage, infarct zone T2 was reduced at day 3 (51.8 (4.6) $\mathrm{ms})(\mathrm{p}<0.001)$, depicting a bimodal pattern.

LV end-diastolic volume increased from baseline to 7 months in patients with myocardial haemorrhage $(\mathrm{p}=0.001)$, but not in patients without haemorrhage $(\mathrm{p}=0.377)$.

\section{Conclusions}

The temporal evolutions of myocardial haemorrhage and oedema are unimodal, whereas infarct zone T2 (ms) has a bimodal pattern in haemorrhagic infarction. Myocardial haemorrhage is prognostically important. Further studies are warranted.

\section{Authors' details}

'Golden Jubilee National Hospital, Clydebank, United Kingdom. ${ }^{2}$ Institute of Cardiovascular and Medical Sciences, BHF Glasgow Cardiovascular Research Centre, Glasgow, United Kingdom. ${ }^{3}$ Robertson Center for Biostatistics, University of Glasgow, Glasgow, United Kingdom.

Published: 27 January 2016 
A. T2 (ms) evolves with a bimodal time-course in patients with myocardial haemorrhage but a unimodal time-course in patients without myocardial haemorrhage.
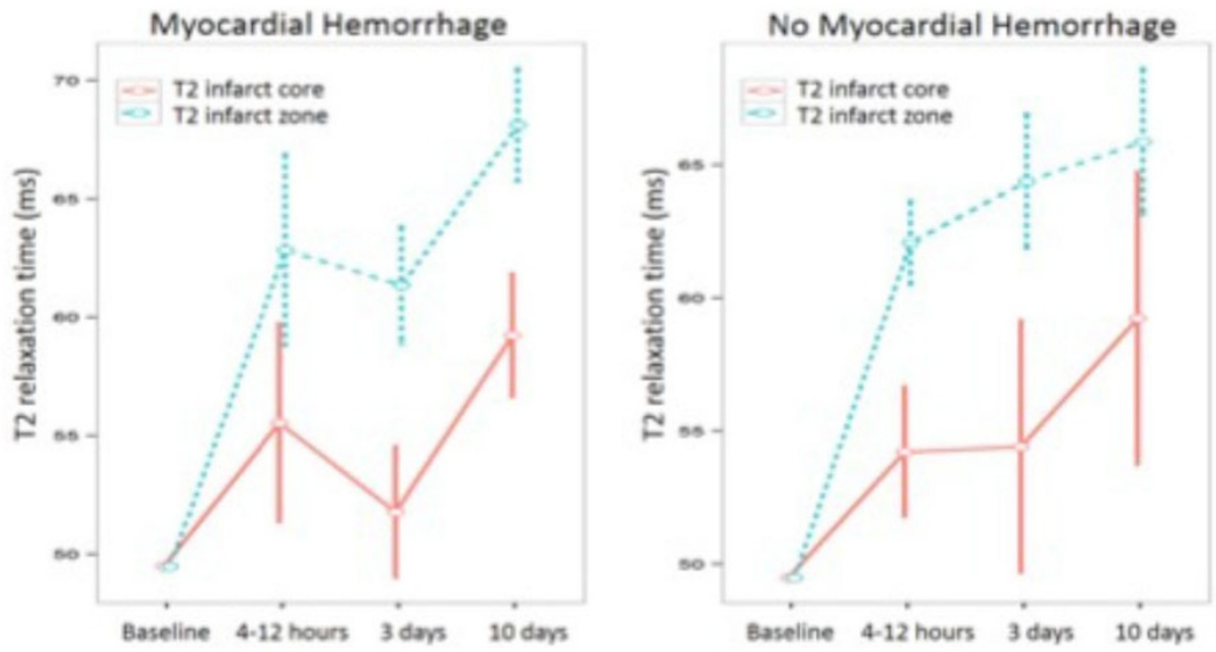

B. Amount of haemorrhage in the sub-group of patients with haemorrhage

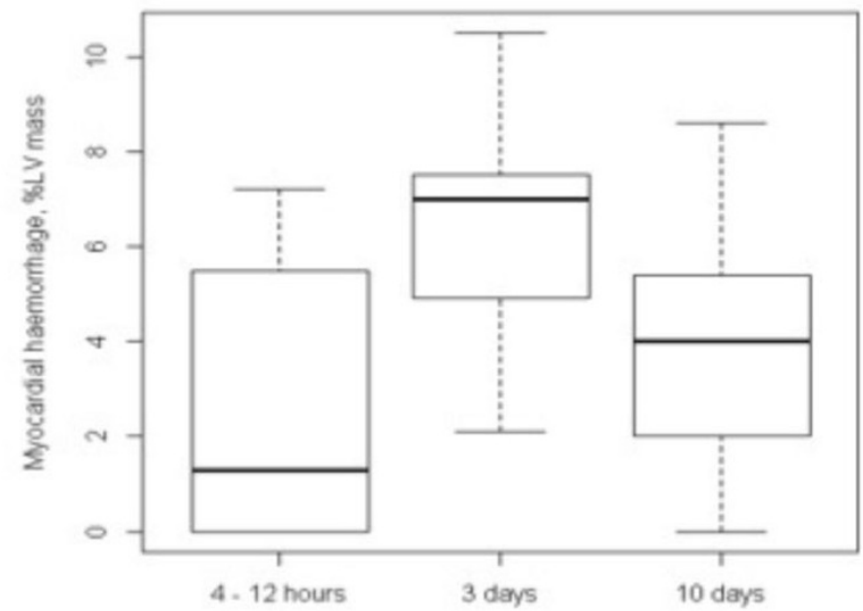

Figure 1

doi:10.1186/1532-429X-18-S1-P231

Cite this article as: Carrick et al:: Myocardial haemorrhage after acute reperfused ST-elevation myocardial infarction evolves progressively and contributes to the early bimodal pattern in T2-relaxation time:

advanced imaging and clinical significance. Journal of Cardiovascular

Magnetic Resonance 2016 18(Suppl 1):P231.
Submit your next manuscript to BioMed Central and take full advantage of:

- Convenient online submission

- Thorough peer review

- No space constraints or color figure charges

- Immediate publication on acceptance

- Inclusion in PubMed, CAS, Scopus and Google Scholar

- Research which is freely available for redistribution 